\title{
Can we develop simple response criteria for slow acting antirheumatic drugs?
}

\author{
D L Scott, J E Dacre, A Greenwood, L Treasure, E C Huskisson
}

\begin{abstract}
The conventional assessment of response to slow acting antirheumatic drugs depends on multiple clinical and laboratory measures. Each measure is analysed separately. For clinical practice and therapeutic trials a single unified classification of response is preferable, based on the most sensitive and simple current measures. Whether or not this was practical was determined in a prospective study of two cohorts of patients: 145 given penicillamine $250-500 \mathrm{mg}$ daily in a single dose; 98 sulphasalazine at an initial dose of $500 \mathrm{mg}$ rising after one month to $2 \mathrm{~g}$ daily. Both groups were followed up for 12 months. A panel of 11 clinical and laboratory measures were evaluated every three to six months. Most changes had occurred by six months, and this was the optimum time to classify response. Four measures were used to devise a five point (0-4) classification of response from no change to remission. The objective was to evaluate if this approach is appropriate; the best level of each measure to use was not determined. The response index was based on: erythrocyte sedimentation rate $<\mathbf{3 0} \mathrm{mm} / \mathrm{h}$; articular index $<3$; morning stiffness $<15 \mathrm{~min}$; $>\mathbf{5 0 \%}$ reduction in joint pain. Similar results were obtained with both drugs. The other clinical and laboratory measures gave limited information. This response index is simple and appropriate. It is suitable for use in clinical practice and drug studies, though the optimal values for dividing each clinical and laboratory variable need to be determined.
\end{abstract}

Treating rheumatoid arthritis (RA) with slow acting antirheumatic drugs (SAARDs) like penicillamine and sulphasalazine results in a fall in clinical assessments of disease activity, such as the duration of morning stiffness and the articular index; reductions in erythrocyte sedimentation rate (ESR) and related acute phase proteins; and a more variable effect on the levels of rheumatoid factor. Prospective trials of SAARDs use a series of clinical variables, laboratory measures, and sometimes radiological assessments to evaluate efficacy. ${ }^{1}$ Each measure is considered separately.

Several overall indices of response have been proposed, including the Mallya and Mace index, ${ }^{2}$ and a similar approach used at Stoke. ${ }^{3}$ There is also an older index described by Lansbury. ${ }^{4}$ These have not been developed logically nor validated. At a recent consensus meeting of 16 rheumatologists at St Bartholomew's the need to devise an acceptable index of response to SAARDs was agreed. ${ }^{5}$ This index should be simple and related to the American Rheumatism Association criteria for remission in RA. ${ }^{6}$

The consensus meeting suggested looking at three clinical measures and one laboratory measure: the articular index, duration of morning stiffness, joint pain, and the ESR (or its equivalent); arbitrary levels for defining response for each of these measures were also proposed. We have examined whether this approach is practical by analysing results in two cohorts of patients with RA treated with penicillamine and sulphasalazine. Our objective was to determine if this was an appropriate method using the levels of response (such as morning stiffness of 15 minutes or less and an ESR of $30 \mathrm{~mm} / \mathrm{h}$ or less) suggested at the consensus meeting; the optimal levels for each of the clinical and laboratory variables will need to be determined in subsequent studies.

\section{Patients and methods \\ PATIENTS}

We studied two different cohorts of patients with RA: (a) 145 treated with penicillamine (250-500 mg daily given as Distamine); (b) 98 treated with sulphasalazine (up to $2 \mathrm{~g}$ daily given as Salazopyrin EN tabs). Penicillamine was given as a single daily dose of 250 or 500 mg. Sulphasalazine was given at an initial dose of $500 \mathrm{mg}$ rising over one month to a maximum of $2 \mathrm{~g}$ daily. Patients were not given greater amounts of either drug if they failed to respond. Some patients given sulphasalazine received lower doses ( 1.0 or $1.5 \mathrm{~g}$ daily) if they had excessive gastrointestinal adverse reactions. Patients received non-steroidal anti-inflammatory drugs and analgesics in maximal possible doses to give symptomatic relief, provided they wished to take these drugs and did not have adverse reactions to them.

The patients were consecutive cases in whom treatment was started with either penicillamine or sulphasalazine in rheumatology clinics in the City and Hackney District. They were separate cohorts and were not randomised. Patients were not preferentially given either drug depending on any specific characteristics of their RA.

They were followed up and assessed in detail at $0,3,6,9$, and 12 months of treatment. Table 1 
Table 1: Characteristics of patients treated with penicillamine and sulphasalazine

\begin{tabular}{lcl}
\hline & Penicillamine & Sulphasalazine \\
\hline Number & 145 & 98 \\
$\begin{array}{l}\text { Mean age (years) } \\
\text { Male:female ratio }\end{array}$ & 50 & 57 \\
$\begin{array}{l}\text { Mean disease duration (years) } \\
\text { Number (\%) completing six } \\
\text { months' treatment }\end{array}$ & 7 & $18: 80$ \\
& $131(90)$ & $70(71)$ \\
\hline
\end{tabular}

Table 2: Response criteria after six months' treatment

\begin{tabular}{ll}
\hline Ritchie articular index & 3 or less \\
Morning stiffness & 15 minutes or less \\
Visual analogue pain score & $50 \%$ reduction or more \\
Erythrocyte sedimentation rate & $30 \mathrm{~mm} / \mathrm{h}$ or less \\
\hline
\end{tabular}

summarises the details of the patients. Treatment was continued for at least six months unless an adverse reaction led to its withdrawal. At this time treatment with SAARD was stopped for those patients who had shown no response at all.

\section{ASSESSMENTS}

A clinical metrologist assessed the following measures initially and then every three months: Ritchie articular index ${ }^{7}$; duration of morning stiffness; mean proximal interphalangeal joint circumference in $\mathrm{mm}$ (using a Geigy gauge); visual analogue pain scale (on a $10 \mathrm{~cm}$ line). Each patient was assessed by the same metrologist. Blood was taken for measurement of ESR; haemoglobin, white cell count and platelet count; latex titre (for rheumatoid factor); and alkaline phosphatase and aspartate aminotransferase.

\section{RESPONSE CRITERIA}

We used four criteria to define response. These were based on the remission criteria for RA devised by Pinals $e t a t^{6}$ and discussions at a

Table 3: Changes over six months in patients receiving penicillamine

\begin{tabular}{lccc}
\hline Variable & $\begin{array}{l}\text { Initial values } \\
\text { Mean }(S D)\end{array}$ & $\begin{array}{l}\text { Final values } \\
\text { Mean }(S D)\end{array}$ & $\begin{array}{l}\text { Mean } \\
\text { percentage } \\
\text { change }\end{array}$ \\
\hline Articular index & $14 \cdot 1(7 \cdot 8)$ & $7 \cdot 9(6 \cdot 4)$ & 44 \\
Morning stiffness (min) & $99(112)$ & $33(74)$ & 67 \\
Pain (mm, visual analogue scale) & $42(31)$ & $19(22)$ & 55 \\
Joint size (mm) & $574(56)$ & $559(54)$ & 3 \\
ESR (mm/h) & $58 \cdot 1(31 \cdot 2)$ & $32 \cdot 4(26 \cdot 2)$ & 44 \\
Platelets $\left(\times 10^{9} /\right)$ & $421(150)$ & $332(119)$ & 21 \\
Haemoglobin (g/l) & $120(18)$ & $128(18)$ & 7 \\
White cell count $\left(\times 10^{9} /\right)$ & $8 \cdot 2(2 \cdot 2)$ & $7 \cdot 8(3 \cdot 9)$ & 5 \\
Alkaline phosphatase (IU/l) & $93(36)$ & $89(38)$ & 4 \\
Aspartate aminotransferase (IU/) & $24 \cdot 8(46 \cdot 8)$ & $19 \cdot 2(8 \cdot 7)$ & 23 \\
Latex titre (reciprocal) & $242(363)$ & $148(309)$ & 39
\end{tabular}

*ESR=erythrocyte sedimentation rate.

Table 4: Changes over six months in patients receiving sulphasalazine

\begin{tabular}{lccc}
\hline Variable & $\begin{array}{l}\text { Initial values } \\
\text { Mean }(S D)\end{array}$ & $\begin{array}{l}\text { Final values } \\
\text { Mean }(S D)\end{array}$ & $\begin{array}{l}\text { Mean } \\
\text { percentage } \\
\text { change }\end{array}$ \\
\hline Articular index & $13 \cdot 5(7 \cdot 8)$ & $9 \cdot 8(8 \cdot 3)$ & 27 \\
Morning stiffness (min) & $114(153)$ & $70(120)$ & 39 \\
Pain (mm, visual analogue scale) & $48(33)$ & $33(28)$ & 31 \\
Joint size (mm) & $566(57)$ & $564(54)$ & 1 \\
ESR $^{*}(\mathrm{~mm} / \mathrm{h})$ & $57 \cdot 5(32 \cdot 5)$ & $37 \cdot 3(26 \cdot 3)$ & 35 \\
Platelets $\left(\times 10^{9} / 1\right)$ & $375(135)$ & $308(107)$ & 18 \\
Haemoglobin (g/l) & $120(19)$ & $122(14)$ & 2 \\
White cell count $\left(\times 10^{9} / 1\right)$ & $8 \cdot 5(2 \cdot 7)$ & $7 \cdot 4(1 \cdot 9)$ & 13 \\
Alkaline phosphatase (IU/1) & $108(48)$ & $108(38)$ & 0 \\
Aspartate aminotransferase (IU/) & $20 \cdot 1(9 \cdot 3)$ & $20 \cdot 7(6 \cdot 5)$ & 3 \\
Latex titre (reciprocal) & $72(80)$ & $61(57)$ & 15 \\
\hline
\end{tabular}

${ }^{*}$ ESR = erythrocyte sedimentation rate. consensus meeting of United Kingdom rheumatologists held at St Bartholomew's Hospital in 1987. 5 Table 2 lists the criteria. Patients could score from 0 to 4: 0 being the most active disease-that is, worst response-and 4 being the least active disease-that is, best response. After preliminary examination of the data at all time points we chose six months as the most appropriate time to define response to treatment.

\section{Results}

The patients receiving penicillamine and sulphasalazine were of similar age and mean disease duration; there were similar numbers of men and women in each group (table 1). Tables 3 and 4 summarise the initial values for each clinical and laboratory variable. A comparison of initial groups showed no significant differences between them in any of the clinical or laboratory variables studied, except the mean latex titre, which was significantly lower in patients receiving sulphasalazine $(p<0.01$ by Wilcoxon rank sum test). There were no differences in the number of seropositive patients in each group.

Tables 3 and 4 show the values after six months' treatment and the percentage changes over six months. The variables showing the greatest percentage changes with both drugs were articular index, morning stiffness, pain, and ESR. These showed mean percentage improvements between $27 \%$ and $67 \%$ over six months and initial values were similar. When patients were followed up for longer periods (up to 12 months) and even during the first three months a similar pattern of response was found, and these variables were still the most sensitive indicators of change (data not shown).

The other variables were less satisfactory for an index. Joint size, haemoglobin, white cell count, and alkaline phosphatase showed less than $20 \%$ change with both drugs. This is too small a change for measuring response. Aspartate aminotransferase and latex titre showed inconsistent degrees of change with both drugs. The platelet count showed $21 \%$ and $18 \%$ mean change with penicillamine and sulphasalazine respectively and has many attractions as an index of response. There was, however, a considerable difference in the initial and final mean platelet counts in patients receiving penicillamine and sulphasalazine and this detracted from its use in determining response.

Table 5 shows the numbers and percentages of response criteria met for patients taking either drug. The $36 / 201(18 \%)$ patients in category 4 did best. The $31 / 201$ (15\%) patients in category 0 did worst and showed no change.

Table 5: Response criteria met at six months. Figures show number $(\%)$ of patients

\begin{tabular}{llll}
\hline $\begin{array}{l}\text { Number of } \\
\text { response } \\
\text { criteria met }\end{array}$ & $\begin{array}{l}\text { Penicillamine } \\
(n=131)\end{array}$ & $\begin{array}{l}\text { Sulphasalazine } \\
(n=70)\end{array}$ & $\begin{array}{l}\text { Total } \\
(n=201)\end{array}$ \\
\hline 4 & $24(18)$ & $12(17)$ & $36(18)$ \\
3 & $27(21)$ & $8(11)$ & $35(17)$ \\
2 & $31(24)$ & $8(11)$ & $39(20)$ \\
1 & $34(26)$ & $26(37)$ & $60(30)$ \\
0 & $15(11)$ & $16(23)$ & $31(15)$ \\
\hline
\end{tabular}


There was a fairly even distribution of patients between each of the five categories (on the $0-4$ scale) with only a slight surfeit of cases in category 1. This distribution was similar with both drugs.

The index was very simple to use. It took less than a minute to classify each patient. No complex decisions were needed and it could be done manually without recourse to a calculator or microcomputer.

\section{Discussion}

Our results show that it is possible to produce a simple classification of response to treatment that can be applied to more than one SAARD. The measures we used were selected after debate among interested rheumatologists. Unlike other indices of disease activity, ${ }^{2-4}$ our proposed index is simple. It can be calculated retrospectively from data in earlier studies of SAARDs. It can also be related to Pinal's criteria of remission in RA. ${ }^{6}$ To define a response index in RA will take time and this study shows the approach is practical; possibly, slight variations may be needed in the actual levels of clinical and laboratory indices chosen to indicate response. There is also a need to define the sensitivity and specificity of the criteria in subsequent investigations.

For response criteria to become widely accepted they must be evaluated in various circumstances by a number of experienced clinicians. The failure of earlier studies of SAARDs to use an agreed definition of response suggests the need for standardisation. All definitions of response have an arbitrary nature. It is possible to argue that an ESR of $30 \mathrm{~mm} / \mathrm{h}$ is not ideal and that, for example, $35 \mathrm{~mm} / \mathrm{h}$ would be better. It is also possible to suggest that other laboratory variables like $\mathrm{C}$ reactive protein should be used. It is reasonable to consider this and plasma viscosity as alternatives to the ESR, but unhelpful to duplicate comparable methods. The dividing lines we selected are supported by consensus views. Six months was chosen for the comparison as by that time patients with $\mathrm{RA}$ should have shown a response to an SAARD, and six months is usually the minimum duration of a study examining one of these drugs.

There are many functional indices which can be used in RA. These include the health assessment questionnaire, ${ }^{8}$ arthritis impact measurement scale, ${ }^{9}$ and the McMaster health index. ${ }^{10}$ We have not attempted to duplicate a functional measure, and the available indices are more than adequate. There has been considerable debate about the merits of using process measures, such as morning stiffness or ESR, in evaluating RA. ${ }^{11}$ Our view is that such discussion is unhelpful, for as long as treatment with SAARDs is based on clinical and laboratory assessments like morning stiffness and ESR they must also be used to define the response to treatment.

The concept of combining measures of response has also been studied by Smythe et al. ${ }^{213}$ They took a more complex statistical approach, based on the 'pooled index'. This is a grand mean of change derived from a series of different measures; these are added using a weighted approach dependent on a transformation of each variable into a standard deviation index. Its drawback is that it is statistically complex and not easily understood by 'statistically naive' clinicians. It has not been widely used.

There have been many new laboratory measures developed to define disease activity in RA, varying from assays for interleukin $1^{14}$ to tests for class specific rheumatoid factors. ${ }^{15} 16$ None of these is accepted as the ideal measure in RA. Until new tests become available we must define our use of simple clinical and laboratory measures. Several groups have looked at the concept of a 'best' marker for monitoring disease $^{17}{ }^{18}$; this includes the novel approach to consensus analysis ${ }^{18}$; but is rather different from an overall index of response.

We hope our index of response will be tested and validated at other centres; we accept the need for this. We suggest it represents a simple, reproducible approach to defining the clinical response to an SAARD. It would be easy to use the response index in routine clinical practice as well as therapeutic studies and it may have direct practical relevance.

We thank Pharmacia Ltd, The Arthritis and Rheumatism Council, the Joint Research Board of St Bartholomew's Hospital, and the North East Thames Regional Research Committee for their support.

1 Huskisson E C. Anti-rheumatic drugs. Eastbourne: Praeger, 1983.

2 Mallya R K, Mace B E. The assessment of disease activity in rheumatoid arthritis using a multivariate analysis. Rheumatology and Rehabilitation 1981; 20: 14-17.

3 Dawes P T, Fowler P D, Collins M, Shadforth M F. Evaluation of an inflammatory index of rheumatoid arthritis. Br F Rheumatol 1986; 25: 206-9.

4 Lansbury J. Report of a three year study on the systemic and articular indices in rheumatoid arthritis: theoretical and clinical considerations. Arthritis Rheum 1958; 1: 502-22.

5 Scott D L, Spector T D, Pullar T, McConkey B. What should we hope to achieve when treating rheumatoid arthritis? Ann Rheum Dis 1989; 48: 256-61.

6 Pinals R S, Masi A T, Larsen R A. Preliminary criteria for remission in rheumatoid arthritis. Arthritis Rheum 1981; 24: 1308-15.

7 Ritchie D M, Boyle J A, McInnes J M, et al. Clinical studies with an articular index for the assessment of joint tenderness in patients with rheumatoid arthritis. $Q \mathcal{F}$ Med 1968; 37 393-8.

8 Fries J F, Spitz P, Kraines R G, Holman H R. Measurement of patient outcome in arthritis. Arthritis Rheum 1980; 23: $137-45$.

9 Meenan R F, Gertman P M, Mason J H. Measuring health status in arthritis. Arthritis Rheum 1980; 23: 146-52.

10 Chambers L W, McDonald L A, Tugwell P, Buchanan W W, Kraag G. The McMaster health index questionnaire as a measure of quality of life for patients with rheumatoid measure of quality of life for patients

11 Woolf A D. Setting the scene and posing the questions. $\mathrm{Br} F$ Rheumatol 1988; 27 (suppl 1): 1-4.

12 Smythe H A, Helewa A, Goldsmith C H. "Independent assessor" and "pooled index" as techniques for measuring treatment effects in rheumatoid arthritis. $\mathcal{f}$ Rheumatol 1977 4: $144-52$.

13 Smythe H A, Helewa A, Goldsmith C H. Selection and combination of outcome measures. 7 Rheumatol 1982; 9 ; $770-4$

14 Eastgate J A, Symons J A, Wood N C, Grinlinton F M, di Giovane $F$, Duff $G \mathbb{W}$. Correlation of plasma interleukin 1 levels with disease activity in rheumatoid arthritis. Lancet 1988; ii: 706-8.

15 Scott D L, Dawes P T, Collins M, Stone R. ELISA assays for IgM and IgG rheumatoid factors: their clinical correlations IgM and IgG rheumatoid factors: their clinical correlations

16 Bampton J L M, Cawston T E, Kyle M V, Hazleman B L. Measurement of rheumatoid factors by an enzyme-linked immunosorbent assay (ELISA) and comparisons with other methods. Ann Rhewom Dis 1985; 44: 13-19.

17 Dixon J S, Hayes S, Constable P D L, Bird H A. What are the "best" measurements for monitoring patients during short-term second-line therapy. $B r \mathcal{J}$ Rheumatol 1988; 27: $37-43$.

18 Bull B S, Levy W C, Westengard J C, et al. Ranking of laboratory tests by consensus analysis. Lancet 1986; ii: 377-80. 